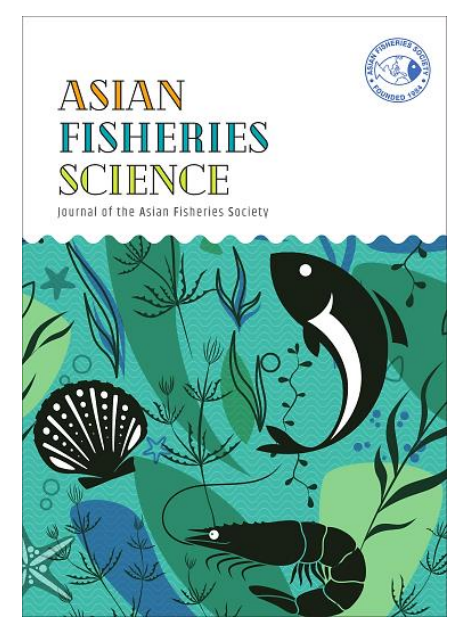

\title{
European Union's Action Plan on Antimicrobial Resistance and Implications for Trading Partners with Example of National Action Plan for Croatia
}

\author{
SNJEŽANA ZRNČIĆ \\ Croatian Veterinary Institute - Laboratory for Fish, Molluscs and Crustacean Diseases, Savska 143, 10000 Zagreb, Croatia
}

*E-mail: zrncic@irb.hr

(c)Asian Fisheries Society

ISSN: 0116-6514

E-ISSN: 2073-3720

https://doi.org/10.33997/j.afs.2020.33.S1.011

\begin{abstract}
The European Union (EU) is addressing antimicrobial resistance (AMR) as a global challenge. A new EU One Health action plan against AMR was issued in 2017 with the goal of preserving the effective treatment of infections in humans and animals, providing a framework for continued, more extensive action to reduce the emergence and spread of AMR, and increasing the development and availability of new effective antimicrobial agents inside and outside the EU. The plan proposes measures to help member states (MS) the proper implementation of antimicrobial stewardship practices to ensure optimal use of antimicrobials and puts forth proposals for new regulations on veterinary medicinal products and medicated feed currently undergoing the ordinary legislative procedure. As a MS, Croatia is putting significant efforts into training and awareness-raising to those who prescribe and use antimicrobials in human and veterinary medicine. The national action plan (NAP) contains: (1) surveillance of AMR of bacteria and reporting to appropriate EU agencies; (2) tracking antimicrobial use (AMU); (3) promotion of responsible use of antimicrobial agents - antimicrobial stewardship; (4) controlling the spread of resistant bacterial strains; (5) awareness-raising on the adverse effects of excessive AMU; and (6) support for the scientific activities through research in AMR by the Ministry of Health, Agriculture and Sciences. An example of the monitoring of AMR in Salmonella, Campylobacter, and indicator Escherichia coli and Enterobacter in poultry, fattening pigs, and calves with regards to a set of antimicrobial agents proposed by the EFSA(European Food Safety Agency) is presented.
\end{abstract}

Keywords: One Health, aquaculture, antibiotics

\section{Introduction}

In recent years, antimicrobial use (AMU) in human and veterinary medicine has increased the threat of development and spread of antimicrobial resistance (AMR). The development of new drugs is insufficient while patient deaths, costs for health care and loss of productivity due to infections caused by resistant pathogens are increasing (EU, 2015). Furthermore, AMR also reduces the ability to safeguard animal health and welfare, with possible repercussions for public health, food safety, and food security (EU, 2016). The European Commission (in further text: Commission) recognised the importance and awareness of AMR in 2001 and the Community Strategy against Antimicrobial Resistance was set up as the first policy instrument addressing AMR at European level (CEC, 2001). This strategy was put in place and is based on four key areas of action: (1) surveillance; (2) prevention and control; (3) research and product development; and (4) international cooperation (COM, 2011). In 2011, the policy was reinforced with the action plan against the rising threats from AMR using the "One Health" approach, covering both the human and animal health sectors. The evaluation of this action plan concluded that Commission had more possibilities to act on the animal than on human health (EU, 2016). That was reflected in the fact that legislative proposal in the veterinary field was created. The One Health action plan was focused on combatting increasing AMR by reducing infections caused by resistant microorganisms (EU, 2016). The drivers responsible for spreading and accelerating the resistant pathogen were defined as: (1) poor hygiene and preventive measures in healthcare settings and at the farm level; 
(2) inappropriate or overuse of antimicrobial agents in human and veterinary medicine; (3) lack of new antimicrobial agents or alternatives; (4) transmission of resistant bacteria from animals to humans either directly or through the food chain; (5) spread caused by contaminated food via the environment, international trade, and travel; and (6) poor awareness and knowledge on AMR in professionals and the general public. To mitigate the adverse effect of these drivers, the action plan defined seven main objectives that were envisaged to be achieved through 12 actions related to human and animal health. The strategy was focused on: (1) prevention of microbial infections and their spread in humans and animals; (2) appropriate AMU in humans and animals; (3) the development of new effective antimicrobial agents or alternatives for treatment; (4) reinforcing research to develop the scientific basis and innovative means to combat AMR; (5) communication, education, and training; (6) strengthening the monitoring and surveillance systems in the human and veterinary fields; and (7) global aspects of AMR.

\section{Evaluation of the EU Action Plan Against Rising Threats from AMR}

In 2015, an evaluation analysis was performed to assess if the 12 key strategic actions (RAND, 2016) of the action plan were the most appropriate actions to combat AMR. The evaluation analysis assessed the relevance of the action plan objectives to the current needs in tackling AMR, and if the approach appropriately involved all sectors (the One Health approach) and aspects of AMR (human medicine, veterinary medicine, animal husbandry, agricultural, research, environment, and trade). The evaluation addressed the relevance, effectiveness, efficiency, internal and external coherence, and EU benefit. It analysed the role of the Commission, member states (MS), associated non-EU member countries so called "thirds countries", and international organisations such as Food and Agriculture Organisation (FAO), the Transatlantic Taskforce on Antimicrobial Resistance (TATFAR), the Organization for Economic Cooperation and Development (OECD), the World Health Organization (WHO), and presented the views of independent experts, researchers, and innovation stakeholders.

The basis for the evaluation of the particular topics came from various documents on "Antimicrobial resistance surveillance in Europe 2011" "Microbial infections up to 2011" (ECDC, 2012; ECDC, 2013), and Antimicrobial agent consumption in the human sector reported in 29 EU/EEA MS (ECDC, 2015). Moreover, a report on antimicrobial agent consumption in the veterinary sector showed a slight decrease (Grave et al., 2014), but a notable decrease of consumption for antimicrobial agents with the highest priority for human medicine was seen. In the evaluation document it was concluded that no significant progress in the development of new antimicrobial agents, their alternatives and diagnostic tools were seen due to the merging of pharmaceutical companies, and that according to European Food Safety Agency (EFSA) documents (2009) the transmission through food chain was not clearly scientifically evidenced and environmental spread caused by contaminated food and water systems is, despite several studies on the spread of the resistant microorganisms, still considered as a knowledge gap. Awareness and knowledge of AMR among participants in surveys varied considerably among MS and also across socio-demographic profiles (Eurobarometer, 2016).

Monitoring and surveillance were dynamic activities coordinated by the EU Commission agencies in the area of health (European Centre for Disease Prevention and Control, ECDC), food (EFSA), and pharmaceuticals (European Medicines Agency, EMA). Data regarding AMR are gathered through the European Antimicrobial Resistance Surveillance Network (EARS-Net) for seven microorganisms of major public health importance (EU, 2012). This network is coordinated and funded by ECDC and annually publishes a report. EFSA coordinated the Scientific Network for Zoonosis Monitoring Data which assisted in gathering and sharing the information on zoonosis in their respective countries. The European Surveillance of Veterinary Antimicrobial Consumption (ESVAC) was launched by EMA to harmonise, collect, and report data on the use of antimicrobial agents in animals. In 2004, the Commission established a EURL-AMR (European Reference Laboratory for AMR) to ensure the quality and standardisation of antimicrobial susceptibility testing.

In the international scene, AMR is a problem for developed and underdeveloped countries and is a major threat to diseases treatments. The Partnership for Pharmaceutical Policy was implemented in 78 African, Caribbean, and Pacific countries, aiming to support the development and implementation of essential medicinal strategies. The EU established bilateral cooperation with the United States of America through TATFAR in the areas of the appropriate therapeutic use of antimicrobial agents in human and veterinary communities, prevention, and strategies for improving the pipeline of new antimicrobial agents. The Commission participated in the preparation of the WHO's Global Strategy for Containment of Antimicrobial Resistance and cooperated with FAO and WHO on the Codex Alimentarius, or "Food Code". The Commission also contributed to the World Organisation for Animal Health (OIE) ad hoc AMR group in the development of Health Codes regarding AMR and animal health. The EURL-AMR collaborated with WHO in supporting activities of the Global Foodborne Infections Network to develop the global standards for monitoring of AMR and capacity building. 
In 2002, MS adopted the Council Recommendation on the prudent use of antimicrobial agents in human medicine and the report on its implementation in 2010 showed that most EU/EEA MS had, or were close to, put in place, a national strategy to contain the problem of AMR (EC, 2002). All MS had implemented a surveillance system and had an action plan covering all topics listed in the Council Recommendation: surveillance of antimicrobial resistance, detection and control of outbreaks, prevention policy, education, and training of health professionals, general public information and research.

Main actions and outputs related to human and animal health are summarised in "Evaluation of the Action Plan against the rising threats from antimicrobial resistance"(RAND, 2016):

- Strengthened promotion of appropriate AMU in human medicine documented in the "Report on the implementation of the Council Recommendation on the prudent use of antimicrobial agents in human medicine" (EU, 2016a), the "Guidelines on prudent use of antimicrobials in human medicine" (ECDC, 2017), and in veterinary medicine documented in the "Guidelines on the prudent use of antimicrobials in veterinary medicine" in (EU, 2015).

- Strengthened regulatory framework on veterinary medicine and medicated feed and adopted the proposal on veterinary medicinal products and medicated feed.

- Strengthened infection prevention and control in healthcare settings documented in the "Report on the implementation of the Council Recommendation on Patient safety" (EU, 2014).

- Adoption of a proposal for an EU Animal Health Law in March 2016 (EU, 2016c).

- Promotion of collaborative research and development of new antimicrobial agents for human patients and promotion of efforts to analyse the needs of new antimicrobial agents in veterinary medicine.

- Development of mutual collaborative commitments for prevention and control of AMR in all sectors, including cooperation on the reduction of environmental pollution by antimicrobial agents particularly from production facilities. The EU contributed to the WHO Global Action Plan, the Global Infection Network, OIE standards, Guideline for Risk Analysis of Foodborne AMR, and TATFAR; and worked with OECD on economic impact. The EU is developing a strategy for pharmaceuticals in the environment.
- For strengthened surveillance systems on antimicrobial agent consumption in human medicine, the European Surveillance on Antimicrobial Consumption (ESAC) and EU AMR Surveillance Network data collection, as part of ECDC's activities, have been improved. At the same time ESCVAC has strengthened surveillance on antimicrobial consumption in veterinary medicine and monitoring and reporting has extended to zoonotic and commensal bacteria in food-producing animals and certain foods (EU, 2013). EFSA, $E M A$, and ECDC reported a first integrated analysis on antimicrobials consumption and resistance in humans and animals in 2015 (ECDC/EFSA/EMA, 2015).

- For reinforced and coordinated research efforts, a Joint Programming initiative for coordinating research activities on AMR has been set up. The Commission supports research activities focused on diagnostic tools, vaccines, and alternative treatments and understanding AMR.

- For communication, education, and training, the European Antibiotic Awareness Day and Eurobarometer on public knowledge on antibiotics were established in 2013 and 2016, respectively.

These actions and outputs were included in the document issued by the Directorate General for Health and Food Safety entitled "Evaluation of the EC Action Plan against the rising threats from antimicrobial resistance, Final Report" (RAND, 2016). This document was used as a background for the preparation of the recent EU action plan on AMR. Despite all undertaken plans and activities, incidences of infections resistant to multidrug therapies and last-resort treatments have significantly increased in the EU in recent years.

\section{Purpose of the Paper}

The purpose of this paper is to summarise the main activities envisaged by the EU action plan on AMR, present the role of the EU on the global plan and the relations, requirements, and implications of this plan for the trading partners/third countries, and give an overview of Croatia's Action Plan, with particular emphasis on the activities in the animal sector.

\section{The European One Health Action Plan Agaínst AMR}

The new action plan was developed based on the 2011 One Health document and was launched in 2017 (EU, 2017). Its main goal is to preserve the possibility of effective treatment of infections in humans and animals by providing a framework for continued, more extensive action to reduce the emergence and spread 
of AMR and to increase the development and availability of new effective antimicrobial agents inside and outside EU. Three pillars are defined as crucial in future activities:

\section{Making the EU a best practice region}

Within the EU, the situation concerning AMR varies across $M S$ and differences are in the effectiveness of national policies to deal with AMU and AMR and occurrence of resistance. The Commission will continue to support the cooperation of all relevant EU scientific agencies (EFSA, EMA, and ECDC) to jointly take appropriate actions and to support and strengthen efforts on better One Health surveillance and AMU and AMR. The EU legislation on AMR monitoring and detection in humans, reporting diseases in humans, identification and assessment of zoonotic bacteria, and consideration of AMR monitoring in the environment will be reviewed and improved.

The vast evidence-based analyses will be used to provide a possible link between consumption of antimicrobials and the occurrence of AMR in humans and food-producing animals and to develop an assessment model of the economic burden of AMR and to estimate the cost-effectiveness of national policies to reduce it. The awareness-raising, public understanding and knowledge sharing on AMU should be highlighted through national awareness programs and contributing to the European Antibiotic Awareness Days.

The EU will promote implementation the EU rules on AMR by sharing information at MS and EU level, supporting One health NAPs, joint actions, increasing assistance of EU Health Security Committee and Commission Working group on AMR in veterinary and food safety area. In cooperation with WHO will help MS to develop and implement own One health NAPS, monitor implementation and organise training programs for competent authorities (CA) through Better Training for Safer Food (BTFS).

Activities in AMR prevention and control will be implemented by infection prevention through control measures in hospital environments, protection of vulnerable groups, promotion of vaccinations in humans, promotion of animal husbandry systems and supporting good animal health and welfare, promotion of prudent use of antimicrobial agents by reserving antimicrobials for human use, reporting the sales and use of antimicrobial agents, developing guidelines for prudent use in human medicine, assisting MS to implement EU guidelines for prudent use in veterinary medicine, and encouraging EMA to review information on benefits and risks of older antimicrobial agents. The EU will better address the role of the environment using the existing data from monitoring programs on pharmaceuticals presence and will reinforce the role of the Scientific Committee on Health and
Environmental Risks (SCHER).

The EU would become a best practice region by development of partnerships against AMR and better availability of antimicrobials by establishing collaboration among key stakeholders in the human and animal health, food, water, and environmental sectors.

\section{Boosting research, development, and innovation on AMR}

Detection, effective infection control, and surveillance should be improved by supporting research on the prevention of development and spread of AMR, its epidemiology and the development of new tools for early detection of resistant pathogens in humans and animals. A new eHealth solution should be implemented to improve prescription practices.

Development of new therapeutics and alternatives for humans and animals should be boosted by the support of Small- and medium-sized enterprises (SMEs) will be supported in research and development of innovative and alternative therapeutic approaches in the treatment and prevention of bacterial infections. European-wide sustainable clinical network will be established to share antimicrobial research data among stakeholders.

The development of new vaccines and new diagnostic tools, wider use of vaccination in medical and veterinary practice, should be fostered and supported. Economic models and incentives gathering evidence for understanding the societal costs and benefits of different strategies for fighting AMR and the development of therapeutics, vaccines, and diagnostics should be developed and explored by MS.

Research on the release of resistant microorganisms and their spread in the environment, monitoring and methods to degrade antimicrobial agents in wastewaters and the environment and risk assessment tools should be supported to close the knowledge gaps of AMR in the environment.

\section{Shaping the global agenda}

The EU and its MS are included in an intensive exchange of people and commodities around the world and policies implemented in one region can have significant impacts elsewhere. Based on the positive effects of EU interventions at the global level, the continued efforts are accentuated in the action plan.

The EU should contribute to the normative work of the WHO, OIE, FAO, and Codex Alimentarius on the development of international frameworks and standards/norms/guidelines related to AMR. 
Technical cooperation in the WHO Global Action Plan on AMR will be reinforced and different international activities aiming to raise political attention to AMR Action in the G7 and G2O UN forums and collaboration within TATFAR (EU, USA, Canada, Norway), and promotion of international regulatory convergence between EMA, FDA, and the Japanese Pharmaceutical and Medical Devices Agency (PMDA) on plans for new antimicrobial agents will be supported.

The EU will consolidate bilateral partnerships by advocating the EU standards and measures for tackling AMR and its implementation by trade partners and their incorporation into cooperative arrangements in trade agreements with major global players and strategic countries (India, China, and Brazil). Capacity building and legislation implementation in candidate and neighbouring countries related to AMR will be supported.

Through cooperation with developing countries, the EU will contribute to reducing AMR by implementing programmes on the prevention and control of infectious diseases, organising workshops and training on capacity building to assist in the development of national strategy in food safety and animal health. The EU will also improve global coordination of research activities, support the establishment of virtual institutes, support subSaharan Africa in collaborative research, and foster international research collaboration on AMR in the animal health sector.

\section{Strategies Regarding AMR in Aquaculture}

The strategies regarding AMR in aquaculture are considered in the "Guidelines for the prudent use of antimicrobials in veterinary medicine" (EU, 2015) and the principle is that similar strategies used for reducing the AMU in terrestrial farm animals should also be used in aquaculture.

Actions to prevent and reduce AMU in aquaculture include implementation of good aquaculture practices that provides the appropriate environmental conditions (water quality, water flow rates, oxygen levels), appropriate feeding, antimicrobial sensitivity testing before treatment, development of specific disease surveillance programs to identify and help prevent possible outbreaks, implementing hygiene (cleaning and disinfection of units between production cycles, keeping separate equipment, boots, and clothes for each unit, etc.), and biosecurity measures (operating an "all-in all-out" system, single-bay management, fallowing between production cycles, quick removal of dead fish, development of systems to avoid disease spread by transport, restriction on access to the farm, etc.). Vaccination against some of the bacterial diseases has been demonstrated effective for reducing AMU and consequently AMR.

\section{Implication of the EU Action Plan on Trading Partners}

The new plan will propose measures to help MS implement antimicrobial stewardship practices to ensure optimal AMU. Furthermore, the Commission proposals for new regulations on veterinary medicinal products and medicated feed, currently undergoing the usual legislative procedure, contains a set of requirements for addressing the threat of AMR including provisions aimed at responsible use of veterinary antimicrobials.

The Commission is gathering information from the main EU trading partners on their policies regarding the fight against the rise of AMR. These include actions taken nationally to monitor the incidence of AMR in bacterial isolates from animals and meat. This information will be used to set the pathways for the Commission's future activities in this area.

The Commission will reinforce its engagement and collaboration with multilateral organisations, such as the WHO, OIE, and FAO, to contribute towards their normative work on the development of international standards related to AMR. This includes the work of the Task Force on AMR recently established by the Codex Alimentarius. The Commission will also promote the inclusion of AMR on the agenda in the next G20 Summit. Finally, to include the AMR issue in an all-new Free Trade Agreements is being systematically proposed and negotiated by the Commission.

\section{National Action Plan on AMR - the Example of Croatia}

Based on the recommendations of the WHO, ECDC, and EC in 2006, the Croatian government issued the decision on the establishment of the Intersectional Coordination Mechanism for the Control of Antimicrobial Resistance (ISKRA), an interdisciplinary session for the control of AMR (Tambić Andrašević, 2009). The first NAP on AMR was implemented from 2009 to 2014 and was prepared according to the EU Action Plan and regulations. Currently, the second NAP is in force from 2015 to 2020 in line with the Global Action Plan on antimicrobial resistance (WHO, 2015) and ECDC Multiannual Strategic Plan (2014).

According to EC Directive (2003b) on the monitoring of zoonoses and zoonotic agents and Decision 2013/652/EU (EU, 2013) on the monitoring and reporting of resistance of zoonotic and commensal bacteria to antimicrobial agents, MS are obliged to ensure monitoring which will provide comparable data on the occurrence of AMR in zoonotic agents and, as far as they present a threat to public health, other agents. General and specific requirements for monitoring are set in the aforementioned documents, including technical specifications on the harmonised monitoring and reporting of AMR in Salmonella, 
Campylobacter, and indicator E. coli and Enterobacter. The manual for the notification of zoonosis, causative agents, and AMR proposes an obligation of reporting. EFSA (2012) issued specific technical specifications with instructions on the monitoring and reporting of AMR. This document precisely describes targeted bacteria, targeted animal species and populations, required samples and targeted antimicrobials, and recommends the modes and places of sampling (farms, slaughterhouses, etc.), testing methods, and interpretation of results. All these documents were used for the preparation of the national surveillance plan on AMR that has been implemented in Croatia since 2011 (Ministarstvo zdravlja RH, 2015).

The animals included in the surveillance are laying hens, broilers, fattening turkeys and pigs, calves younger than one year, sheep, goats, dairy cattle, and young bovine. The samples, swabs, or coecal splash should be collected on farms and in slaughterhouses to be analysed for the presence of Salmonella, Campylobacter, and commensal bacteria like E. coli and Enterobacter. Sets of antimicrobial compounds are proposed as well as methods for the determination of epidemiological cut-off values (ECOFFs), clinical breakpoints, and concentration ranges to be tested. Results of the surveillance are reported to the Ministry of Agriculture, Veterinary Directorate, and EURL-AMR where data from all MS are analysed, compared, and finally published on their webpage.

\section{Conclusion}

The Council of the EU has issued conclusions on the next steps under the One Health approach to combat AMR (EU, 2016b) that welcomes former activities, acknowledges many efforts, and highlights the future actions that are of the utmost importance.

They welcome the Global Action Plan on AMR developed by WHO, FAO, and OIE, the Resolution on Antimicrobial Resistance adopted in 2015 by the FAO, the Resolution combating Antimicrobial Resistance and promoting the prudent use of antimicrobial agents in animals by OIE, the Codex Alimentarius Commission initiative concerning the need to review and update standards, codes, and guidelines related to AMR and other international and regional initiatives such as the declaration by the G7 on AMR and the decision to put AMR on the agenda of the G20.

In the EU Council document, it is recalled that AMR is a cross-border health threat that cannot be sufficiently addressed by single MS, cannot be confined to a geographical region or MS, and hence requires intensive cooperation and coordination between MS. The document also acknowledges that several legislative and non-legislative measures have already been taken and are taken at the EU level to coordinate and ensure a common EU approach for reducing the risk of AMR in the veterinary sector.
These measures include regulation on additives for use in animal nutrition, prohibiting the use of antibiotics as growth promoters (EC, 2003a), Commission Implementing Decision on the monitoring and reporting of antimicrobial resistance in zoonotic and commensal bacteria (EU, 2013), Commission Decisions on modifications of marketing authorisations for products containing critically important antimicrobials to reflect specific measures against the development of AMR, and the Guidelines for the prudent use of antimicrobials in veterinary medicine (EU, 2015).

The Council expresses its concern regarding the estimation that about 700,000 deaths may be caused globally each year by AMR (Review on Antimicrobial Resistance, 2014). The economic impact associated with current rates of AMR in OECD countries may reach about $0.03 \%$ of GDP in 2020, $0.07 \%$ in 2030, and $0.16 \%$ in 2050 , resulting in cumulative losses of about USD 2.9 trillion by 2050 .

The scientific opinions and reports on antimicrobial resistance published by the ECDC, EFSA, and EMA are acknowledged, as well as the ongoing work on the economic impact of AMR carried out by OECD and the World Bank.

Finally, they underline that in order to stimulate the development of new antimicrobial agents, alternative therapies, and rapid diagnostics, EU and global coordination and cooperation on research programs and incentives are needed.

Due to the complexity of the problem - its crossborder dimension and high economic burden - the impact of AMR goes beyond its severe consequences for human and animal health and has become a global public health concern that affects the society and requires urgent and coordinated intersectoral action based on the precautionary principle.

To make progress in the fight against AMR, the new EU action plan should contain measurable and clearly defined quantitative or qualitative goals, benchmarks, and effective measures to achieve these goals. The success of the fight against AMR relies heavily on the commitment and willingness of governments to take action to ensure the implementation of the initiatives under the One Health approach involving all relevant sectors and on the will of the EU MS to cooperate within the EU and at an international level.

\section{References}

CEC. 2001. Communication from the commission on a Community Strategy against antimicrobial resistance. Brussels, COM, 0333 final Vol. I. 19 pp. https://eur-lex.europa.eu/legal-content/EN/TXT l?uri=LEGISSUM:c11568 (Accessed 18 Sept 2020).

Cecchini M., Langer J. \& Slawomirski, L. 2015. Antimicrobial resistance in $\mathrm{G} 7$ Countries and beyond: Economic issues, policies and options for action. OECD. 75 pp. https://www.oecd.org/els/health- 
systems/Antimicrobial-Resistance-in-G7-Countries-and-Beyond.pdf (Accessed 18 September 2020)

COM. 2011. Communication from the Commission to the European Parliament and the Council. Action plan against the rising threats from antimicrobial resistance. Brussels, 15.11.2011., 748 final. https://ec.europa.eu/transparency/regdoc/rep/1/2011/EN/1-2011748-EN-F1-1.Pdf (Accessed 18 September 2020).

EC (European Community). 2001. Directive 2001/82/EC of the European Parliament and of the Council on the on the Community code relating to veterinary medicinal products. Official Journal L 311:1-66. http://data.europa.eu/eli/dir/2001/82/oj (Accessed 8 Aug 2019).

EC. 2002. Council Recommendation on the prudent use of antimicrobial agents in human medicine. Official Journal L 34: 13-16. http://data.europa.eu/eli/reco/2002/77/oj(Accessed 8 August 2019).

ECDC (European Centre for Disease Prevention and Control). 2012. Antimicrobial resistance surveillance in Europe 2011. Annual report of the European Antimicrobial Resistance Surveillance Network (EARS-Net). Stockholm, ECDC.

https://www.ecdc.europa.eu/sites/default/files/media/en/publications /Publications/antimicrobial-resistance-surveillance-europe2011.pdf (Accessed 8 August 2019).

ECDC. 2013. Surveillance of surgical site infections in Europe, 20102011. ECDC, Stockholm. 55 pp. https://www.ecdc.europa.eu Isites/default/files/media/en/publications/Publications/SSI-ineurope-2010-2011.pdf (Accessed 8 August 2019).

ECDC. 2015. Surveillance report. Annual epidemiological report. Antimicrobial resistance and healthcare-associated infections 2014. 23 pp. https://www.ecdc.europa.eu/sites/portal/files/media/en /publications/Publications/antimicrobial-resistance-annualepidemiological-report.pdf (Accessed 18 August 2019).

ECDC, EFSA, EMA. 2015. ECDC/EFSA/EMA first joint report on the integrated analysis of the consumption of antimicrobial agents and occurrence of antimicrobial resistance in bacteria from humans and food-producing animals. ECDC/EFSA/EMA, Stockholm/Parma/London. EFSA Journal 13:4006, 114 pp. https://doi.org/10.2903/j.efsa.2015.4006

https://www.ecdc.europa.eu/sites/default/files/media/en/publicati ons/Publications/antimicrobial-resistance-JIACRA-report.pdf (Accessed 18 August 2019).

ECDC. 2016. Surveillance and disease data for antimicrobial consumption. https://ecdc.europa.eu/en/antimicrobial$\begin{array}{lll}\text { consumption/surveillance-and-disease-data } & \text { (Accessed } & 18\end{array}$ September 2018).

EFSA (European Food Safety Agency). 2009. Joint opinion on antimicrobial resistance focused on zoonotic infections. EFSA Journal 7:1372. $\quad \underline{\text { https://efsa.onlinelibrary.wiley.com }}$ /doi/abs/10.2903/j.efsa.2009.1372 (Accessed 18 September 2020).

EFSA. 2012. Scientific report of EFSA. Technical specification on the harmonized monitoring and reporting of antimicrobial resistance in Salmonella, Campylobacter and indicator Escherichia coli and Enterococcus spp. Bacteria transmitted through food. EFSA Journal 10:2742. https://doi.org/10.2903/j.efsa.2012.2742

EU (European Union). 2003a. Regulation 1831/2003/EC of the European Parliament and of the Council on additives for use in animal nutrition. Official Journal L 268:29-43. https://eur-lex.europa.eu/legalcontent/EN/TXT/PDF/?uri=CELEX:32003R1831\&from=EN (Accessed 18 September 2020).

EU Eurobarometer. 2016. Special Eurobarometer 445. Report antimicrobial resistance. April 2016. 115 pp. https://doi.org/10.2875/760366 https://ec.europa.eu/health/sites/health/files/antimicrobial_resista nce/docs/eb445_amr_generalreport_en.pdf (Accessed 18 September 2020).

EU (European Union). 2003a. Regulation 1831/2003/EC of the European Parliament and of the Council on additives for use in animal nutrition. Official Journal L 268:29-43. https://eurlex.europa.eu/legal-

content/EN/TXT/PDF/?uri=CELEX:32003R1831\&from=EN (Accessed 18 Sept 2020).

EU. 2003b. Directive 2003/99/EC on the monitoring of zoonoses and zoonotic agents, amending Council Decision 90/424/EEC and repealing Council Directive 92/117/EEC. Official Journal L 325:31-40. https://eur-lex.europa.eu/legal-content/EN/TXT/PDF

l?uri=CELEX:32003L0099\&from=EN (Accessed 18 September 2020).

EU. 2012. Commission Implementing Decision 2012/506/EU amending Decision 2002/253/EC laying down case definitions for reporting communicable diseases to the Community network under Decision No 2119/98/EC of the European Parliament and of the Council (notified under document C (2012) 5538). Official Journal L 262:1-57. http://data.europa.eu/eli/dec_impl/2012/506/oj (Accessed 18 September 2020).

EU. 2013. Commission Implementing Decision 2013/652/EU on the monitoring and reporting of antimicrobial resistance in zoonotic and commensal bacteria. Official Journal L 303: 26-39. http://data.europa.eu/eli/dec_impl/2013/652/oj (Accessed 8 August 2019).

EU. 2015. Commission Notice 2015/C 299/04. Guidelines for the prudent use of antimicrobials in veterinary medicine. Official Journal C 299:7-26.

https://ec.europa.eu/health/sites/health/files/antimicrobial_resista nce/docs/2015_prudent_use_quidelines_en.pdf (Accessed 8 August 2019).

EU. 2016a. Commission staff working document. Evaluation of the action plan against the rising threats from antimicrobial resistance. Brussels, SWD, 0347 final. 148 pp. http://ec.europa.eu/health lamr/sites/amr/files/amr_evaluation_2011-16_evaluation-actionplan.pdf (Accessed 8 August 2019).

EU. 2016b. Council conclusions on the next steps under a One Health approach to combat antimicrobial resistence. Press release, 349/16 of 17.06.2016. https://www.consilium.europa.eu/en/press/pressreleases/2016/06/17/epsco-conclusions-antimicrobial-resistance (accessed 18 September 2020)

EU. 2016c. Regulation (EU) 2016/429 of the European Parliament and of the COUNCIL of 9 March 2016 on transmissible animal diseases and amending and repealing certain acts in the area of animal health ('Animal Health Law'). Official Journal of the European Union L 84: 1208. https://eur-lex.europa.eu/legal-content/EN/TXT/PDF I?uri=CELEX:32016R0429\&from=EN (Accessed 8 August 2019).

EU. 2017. A European One-Health action plan against antimicrobial resistance (AMR). Brussels, SWD, 0240 final. 22 pp.

https://ec.europa.eu/health/sites/health/files/antimicrobial_resista nce/docs/amr_2017_action-plan.pdf (Accessed 8 August 2019).

Grave, K., Torren-Edo, J., Muller, A., Greko, C., Moulin, G., Mackay, D., ESVAC Group. 2014. Variation in the sales and sales patterns of veterinary antimicrobial agents in 25 European countries. Journal of Antimicrobial Chemotherapy 69:2284-2291. https://doi.org/10.1093 ljac/dku106

Ministarstvo zdravlja Republike Hrvatske. 2015. Nacionalni program za kontrolu otpornosti bakterija na antibiotike 2015-2020.

RAND Europe. 2016. Evaluation of the EC Action Plan against the rising 
threats from antimicrobial resistance. https://ec.europa.eu /health/amr/sites/amr/files/amr_final-report_2016_rand.pdf

(Accessed 18 September 2020).

Tambić Andrašević, A. 2009. Antibiotic resistance control in Croatia. Croatian Journal of Infection 29:145-150. https://doi.org/10.21860 Imedflum2018_203562

WHO (World Health Organization). 2015. Global action plan on antimicrobial resistance. Official records of the sixty-eighth World Health Assembly (document WHA68/2015/REC/1, Annex 3.

http://www.wpro.who.int/entity/drug_resistance/resources/global_ action_plan_eng.pdf (Accessed 8 August 2019). 